\title{
CORTICOSTEROIDS AND FIBROLYSIN IN THE PREVENTION OF LACRIMAL DUCT OBSTRUCTION*
}

\author{
BY \\ Y. DAYAL \\ Gandhi Eye Hospital and M.U. Institute of Ophthalmology, Aligarh, India
}

BLOCKED naso-lacrimal duct, i.e. stenosis without inflammation, is the commonest cause of epiphora. Medical treatment to cure the condition has been recommended from early times, but on the whole, with few exceptions, the results have not been good.

Anel (1713) first attempted to restore the patency of the passages by probing and syringing. Apart from these methods, conservative treatment depended on heat and continuous firm pressure (Fabricius ab Aquapendente, 1723). Subsequently other modifications to Anel's method were suggested, the best being the progressive probing introduced by Bowman (1857). Ziegler $(1910,1922)$ in America popularized the use of thicker probes. More recently bacteriostatic drugs have been used to control the infection along with the syringing and probing, and have been shown to cure some cases without surgical intervention (Duke-Elder, 1952).

The present study was designed to improve the rate of cure by conservative treatment, by using corticosteroids and fibrolysin (drugs known for their anti-inflammatory and anti-fibrotic activities respectively) in addition to the usual antibiotics following probing.

\section{Material}

A series of 82 patients ( 93 eyes) with epiphora due to blocked naso-lacrimal duct was selected for study at the Gandhi Eye Hospital, Aligarh, during 1959 and 1960.

The duration of the epiphora varied from 3 months to 2 years. The patients were mostly middle-aged adults (range 16 to 52 yrs). There were 59 females and 23 males. The right eye was affected in 46 cases and the left in 25 , and eleven were bilateral.

\section{Method}

In each case the site of the obstruction was confirmed by syringing, and before it was included in the present study, a smear and culture were done to exclude inflammation or infection.

* Received for publication February 13, 1961. 
The cases thus selected were studied in four separate groups:

Group I: Twenty cases (22 eyes) were probed and then syringed with an antibiotic solution (penicillin with streptomycin) daily for 12 days.

Group II: 21 cases ( 25 eyes) were probed and then syringed with a corticosteroidantibiotic solution (Efcorlin with Neomycin) daily for 12 days.

GrouP III: Nineteen cases (20 eyes) were probed and then syringed with both an antibiotic solution (penicillin with streptomycin) and a fibrolysin solution daily for 12 days. Syringing with antibiotics was done in the morning and that with fibrolysin in the afternoon.

Group IV: 22 cases ( 26 eyes) were probed and then syringed with a corticosteroidantibiotic solution (as in Group II) and a fibrolysin solution (as in Group III) daily for 12 days, in the morning and afternoon respectively.

Only patients in whom the probing was successful were given the daily syringing. The following drugs were used:

(i) Penicillin-Streptomycin Solution.-Crystalline penicillin G in 5,000 units per $\mathrm{ml}$. and streptomycin 2 per cent in distilled water.

(ii) Corticosteroid-Antibiotic Solution.-Efcorlin with Neomycin eye drops (Glaxo Laboratories, India) containing hydrocortisone acetate 1 per cent, and Neomycin sulphate 0.5 per cent.

(iii) Fibrolysin.-(E. Merck, A.G., Darmstadt) in 2-ml. ampoules.

After the 12 days' syringing the patients were given astringent eye-drops (to be instilled into the conjunctival sac), and were advised to report for a check-up after about 6 weeks, when recurrence of epiphora, if any, was noted and the patency of the naso-lacrimal duct was confirmed by syringing. The patients reported for this check-up after periods ranging from 5 to 9 weeks (average 7).

\section{Results}

The Table shows that the percentage success rate was lowest in Group I and highest in Group IV.

TABLE

NUMBERS TREATED AND SUCCESS RATE IN EACH GROUP

\begin{tabular}{c|c|c|c|c|c|c|c}
\hline Group & Solution & $\begin{array}{c}\text { No. of } \\
\text { Cases }\end{array}$ & $\begin{array}{c}\text { No. of } \\
\text { Eyes } \\
\text { Probed }\end{array}$ & $\begin{array}{c}\text { No. of } \\
\text { Eyes } \\
\text { Syringed }\end{array}$ & \multicolumn{2}{|c|}{ No. Successfully Syringed } & \multicolumn{2}{c}{$\begin{array}{c}\text { Success } \\
\text { Rate } \\
\text { (per cent.) }\end{array}$} \\
\hline I & Antibiotic & 20 & 22 & 16 & 9 & 51 \\
\hline II & $\begin{array}{c}\text { Antibiotic }+ \\
\text { Corticosteroid }\end{array}$ & 21 & 25 & 18 & 15 & 11 & 61 \\
\hline III & $\begin{array}{c}\text { Antibiotic }+ \\
\text { Fibrolysin }\end{array}$ & 19 & 20 & 15 & 11 & 10 & 66 \\
\hline IV & $\begin{array}{c}\text { Antibiotic }+ \\
\text { Corticosteroid } \\
+ \text { Fibrolysin }\end{array}$ & 22 & 26 & 19 & 17 & 16 & 84 \\
\hline
\end{tabular}




\section{Discussion}

The pathology of the blocked duct is still not very clear. There may be a simple congestion of the mucous membrane followed by chronic inflammation at the narrow points of the tear-way (Valière-Vialeix, 1939), which may lead to fibrosis. This probably explains why medical treatment has not been very effective in spite of repeated probings. After probing, in spite of controlling the infection by syringing with bacteriostatic drugs (Duke-Elder, 1952), there are many recurrences. Probing invariably traumatizes the tissues, causing inflammation of the mucosa, and the subsequent cicatrization and stenosis causes a recurrence of the inflammation.

If the post-probing inflammation and cicatrization can be checked the problem of lacrimal obstruction can be tackled by probing alone, though cases in which probing fails will still have to undergo surgery. Various local drugs have been tried to counteract inflammation and fibrosis as well as infection after probing.

von Herrenschwand (1954) mentioned the use of cortisone ointment 1 per cent. to increase the elasticity of the punctum in cases showing senile changes, but this is the first time cortisone has been tried in cases of lacrimal obstruction. Combined corticosteroids and antibiotics for syringing have had the desired anti-inflammatory and anti-infective effect.

Fibrolysin is a compound of thiosamine and sodium salicylate. It is well absorbed by the tissues locally and is said to possess the specific property of softening the cicatrix. It probably acts on the newly-formed connective tissue by absorbing the inflammatory deposits and thereby checking the consequent fibrosis. In ophthalmology its local and systemic use has hitherto been mainly restricted to cases of corneal opacity.

In the present study the combination of fibrolysin with antibiotics and corticosteroids attacked the infection, inflammation, and cicatrization simultaneously and the excellent results achieved in maintaining the patency of the naso-lacrimal duct are shown by the 84 per cent. success rate in Group IV (see Table).

\section{Summary}

(1) 82 cases of epiphora due to blocked naso-lacrimal duct are reported. Those in which probing was successful were then syringed daily for 12 days with antibiotics, corticosteroids, and fibrolysin separately and combined.

(2) The results of four different treatment schedules are compared.

(3) The simultaneous use of antibiotics, corticosteroids, and fibrolysin for syringing following probing maintained the patency of the naso-lacrimal duct in 84 per cent. of eyes treated. 
(4) This combined therapy was designed to control the three processes of infection, inflammation, and cicatrization.

I wish to thank the Chief Medical Officer, Gandhi Eye Hospital, Aligarh, for the facilities to undertake this study, and also Dr. R. Singh for his help in its earlier stages.

\section{REFERENCES}

ANEL, D. (1713). " "Sur la fistule lacrimale”, Zappatte, Turin. (Cited by Duke-Elder, 1952.) Bowman, W. (1857). Ophthal. Hosp. Rep., 1, 10.

DUKE-ELDER, S. (1952). "Text-book of Ophthalmology", vol. 5, p. 5300. Kimpton, London.

FABRICIUS, H. (1723). "Opera chirurgica". Leyden.

HeRrenschwand, F. von (1954). Klin. Mbl. Augenheilk., 125, 657.

JACOBS, H. B. (1959). Brit. J. Ophthal., 43, 415.

VALIÈRE-VIALEIX, V. (1939). In "Traité d'ophtalmologie", ed P. Bailliart and four others, vol. 4, p. 164. [Société française d'ophtalmologie]. Masson, Paris.

ZIEGLER, S. L. (1910). J. Amer. med. Ass., 54, 2026.

(1922). Ibid., 78, 1701. 